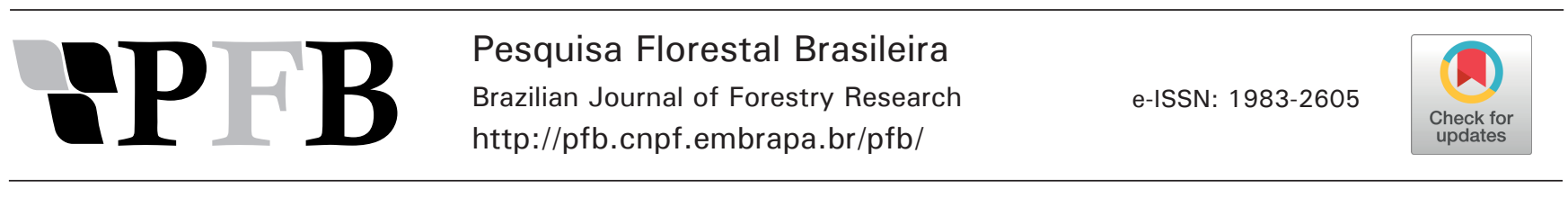

\title{
Desempenho de espécies de Eucalyptus para uso em sistemas de integração floresta-pecuária no bioma Pampa
}

\author{
Jorge Ribaski1 ${ }^{10}$ \\ ${ }^{1} E m b r a p a$ Florestas, Estrada da Ribeira, Km 111, CP. 319, CEP 83411-000, Colombo, PR, Brasil
}

"Autor correspondente:

jorge.ribaski@embrapa.br

Termos para indexação:

Adaptabilidade

Análise de crescimento

Produção de madeira

Index terms:

Adaptability

Growth analysis

Wood production

Histórico do artigo:

Received in 17/04/2018

Accepted in $17 / 09 / 2018$

Published in 29/12/2018

doi: 10.4336/2018.pfb.38e201801638

\begin{abstract}
Resumo - Objetivou-se avaliar o desempenho de Eucalyptus grandis, E. dunnii, E. benthamii, E. badjensis e do híbrido $E$. urograndis, em relação à sobrevivência e produtividade florestal em uma área experimental implantada no município de Alegrete, RS. Os sistemas de integração floresta-pecuária foram compostos por linhas triplas de árvores, plantadas no espaçamento $3 \mathrm{~m}$ x $2 \mathrm{~m}$ e distanciadas entre si em $30 \mathrm{~m}$, resultando numa densidade inicial de 417 árvores ha ${ }^{-1}$, o que corresponde a 22,2\% de área ocupada pelas faixas dos renques das árvores, ficando o restante da área destinada à atividade pecuária $(77,8 \%)$. As medições de diâmetro a $1,3 \mathrm{~m}$ acima do nível do solo (DAP) e das alturas das árvores foram feitas anualmente, até os sete anos de idade. O delineamento experimental foi inteiramente casualizado, com seis repetições por tratamento, e o software Assistat foi utilizado nas análises estatísticas. O desempenho de Eucalyptus grandis e E. urograndis tiveram destaque, em relação à sobrevivência, crescimento e produtividade, diferente de $E$. dunnii e $E$. benthamii que não apresentaram bom desempenho. E. badjensis não deve ser recomendado para plantios em condições ambientes análogas à dessa pesquisa.
\end{abstract}

\section{Performance of Eucalyptus species to be used in forest-livestock integration systems in Pampa biome}

\section{Introdução}

A região sudoeste do estado do Rio Grande do Sul, no bioma Pampa, possui extensas formações arenosas com baixa aptidão para agricultura. $\mathrm{O}$ uso tradicional da terra para a criação extensiva de gado tem acelerado o processo de erosão eólica e hídrica, devido à fragilidade natural desses solos (Flores et al., 2010). Esse processo 
de degradação ambiental, aliado ao precário desempenho da pecuária extensiva, cujos resultados, na maioria das vezes, apresentam indicadores de eficiência econômica baixa ou negativa (Costa et al., 2006; Nabinger et al., 2009; Ribaski et al., 2009; Ruviaro et al., 2016), são os principais fatores que têm refletido negativamente sobre as condições socioeconômicas da região.

Diante disso, percebe-se no meio rural a premente necessidade de mudanças significativas na forma de utilização da terra, aonde os aspectos relativos à sustentabilidade ambiental e a criação de novas alternativas socioeconômicas vêm assumindo importância cada vez maior para os produtores dessa região (Ribaski et al., 2009). Alguns estudos mostram consenso sobre a necessidade de diversificação da matriz produtiva, visando melhorar a rentabilidade do sistema produtivo (Carvalho et al., 2006; Ilha et al., 2006; Inácio \& Senna, 2014; Varella et al., 2016). Resultados de pesquisas desenvolvidas na região mostram que a introdução do componente florestal na propriedade, de forma homogênea ou por meio dos sistemas silvipastoris, apresenta a possibilidade de geração de emprego e incremento da renda com maior eficiência que a pecuária extensiva da região (Ribaski et al., 2009; Varella et al., 2012).

Os plantios florestais tiveram início no Rio Grande do Sul há mais de 100 anos para o atendimento de demandas nas próprias propriedades rurais. No pampa gaúcho, o eucalipto era plantado, principalmente, para formar quebra-ventos, servindo também para abrigo do gado e, posteriormente, para suprir lenha para fogões e para o tradicional fogo de chão, sendo também utilizado para moirões de cerca e construções rurais (Associação Gaúcha de Empresas Florestais, 2015).

Atualmente, existe uma grande demanda por madeira na região, principalmente para propósitos energéticos, tendo o Estado consumido 7,2 milhões de $\mathrm{m}^{3}$ de lenha em 2015, com destaque para o eucalipto como a principal fonte de lenha, representando $78 \%$ do consumo (Associação Gaúcha de Empresas Florestais, 2016). O segmento agropecuário e o setor residencial são os principais consumidores de lenha, representando mais da metade do total consumido no Estado. O segmento industrial é apenas o terceiro consumidor de lenha, com destaque para produção de cerâmica. Como relação à madeira para serraria, o Rio Grande do Sul foi responsável por $6 \%$ da produção nacional, em 2015 , produzindo cerca de $560 \mathrm{mil} \mathrm{m}^{3}$ de madeira serrada
(Associação Gaúcha de Empresas Florestais, 2016). Entretanto, alguns aspectos ainda limitam a produção de madeira de Eucalyptus em maior escala na região, devido a fatores adversos, como por exemplo geadas e secas severas (Silva et al., 2009; Caron et al., 2011).

O eucalipto ao longo da sua evolução natural desenvolveu mecanismos adaptativos eficientes para crescer rapidamente sob condições favoráveis e também suportar estresse hídrico, de temperatura e nutricional. Ainda assim, o plantio de eucaliptos no bioma Pampa deve ser cuidadosamente analisado, por haver riscos na fase de implantação devido à ocorrência de geadas, as quais ocorrem na região entre maio e agosto (Brixner et al., 2014). Além desse fenômeno climático, a ocorrência de déficit hídrico também é um fator de risco importante para as plantas, principalmente na fase inicial de plantio, por não estarem suficientemente bem enraizadas.

Com relação às opções de germoplasmas que reúnem as características de tolerância ao frio e à seca, viabilidade de propagação clonal e múltiplos usos da madeira, um número muito pequeno de alternativas para plantação está disponível em regiões propensas a eventos climáticos de forte intensidade (Moraes et al., 2015; Santos et al., 2015).

Dentre as espécies de eucalipto economicamente importantes para as condições climáticas da Região Sul do Brasil, e que apresentam boa aptidão para produção de madeira para fins energéticos e também para serraria, a Embrapa Florestas tem desenvolvido pesquisas prioritariamente com as espécies Eucalyptus dunnii, E. benthamii, E. badjensis, E. grandis e E. saligna (Paludzyszyn Filho et al., 2006; Moraes et al., 2015; Santos et al., 2015), sendo as três primeiras as mais indicadas para regiões mais propensas a geadas severas (latitudes entre os paralelos $24^{\circ}$ e $32^{\circ} \mathrm{S}$ ) (Santos et al., 2015).

Esse trabalho teve por objetivo avaliar a performance de cinco diferentes espécies de eucalipto, em relação ao percentual de sobrevivênca e produtividade florestal, visando a sua utilização em sistemas de integração floresta-pecuária (sistemas silvipastoris) no bioma Pampa do Rio Grande do Sul.

\section{Material e métodos}

Aárea de estudo localiza-se no município de Alegrete,

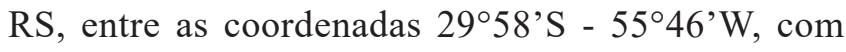
altitude de $105 \mathrm{~m}$. O município está localizado na 
fronteira oeste do Rio Grande do Sul, sendo o maior município em extensão de terras do estado. O clima da região, segundo a classificação de Köppen, é do tipo cfa, subtropical com verões quentes (Köppen, 1936; Pell et al., 2007; Alvares et al., 2013). A média de precipitação pluviométrica é de $1.525 \mathrm{~mm}$ anuais. A menor média de precipitação acontece em agosto e a maior em outubro (Soares et al., 2016). Devido à variabilidade sazonal das chuvas na região da fronteira oeste do Estado, há períodos de seca que causam perdas significativas na produção agrícola (Ben et al., 2016), sendo que o município de Alegrete, segundo Maluf (2000), apresenta uma deficiência hídrica anual de $16 \mathrm{~mm}$. O Solo da área do experimento é classificado como Argissolo Vermelho Eutrófico arênico, com horizonte A moderado, de textura arenosa média e relevo suave ondulado (Flores et al., 2010; Santos et al., 2013).

A formação de geadas no município de Alegrete, RS, ocorre entre o final de maio e o final de agosto (Matzenauer et al., 2011), e de junho e julho são os meses com condições mais favoráveis à formação de geada (Brixner et al., 2014). Nesse mesmo estudo os autores, considerando um intervalo entre início de abril e final de novembro, de uma série histórica de 49 anos para o risco diário de formação de geada, observaram a ocorrência de aproximadamente 100 dias com temperatura mínima absoluta do ar de $3{ }^{\circ} \mathrm{C}$ ou menos, o que equivale a uma temperatura em torno de $-1{ }^{\circ} \mathrm{C}$ ou menor na relva.

Foram utilizadas mudas do clone SVR3709, resultante do cruzamento entre Eucalyptus grandis W. Hill ex. Maiden com E. urophylla S.T. Blake (E. urograndis). Estas mudas foram obtidas junto à Empresa Votorantim Celulose e Papel S.A. - VCP (atualmente Fibria). As espécies E. dunnii, E. benthamii e E. badjensis tiveram suas mudas produzidas por sementes no viveiro da Embrapa Florestas. As mudas de E. grandis foram adquiridas de um viveiro comercial no Rio Grande do Sul. As características desses materiais genéticos estão detalhadas na Tabela 1.

Tabela 1. Características dos materiais genéticos referentes às cinco espécies de Eucalyptus implantadas no ensaio experimental em Alegrete, RS.

Table 1. Genetic material characteristics of the five Eucalyptus species used in the experimental test in Alegrete, Rio Grande do Sul State.

\begin{tabular}{clcc}
\hline Tratamento & \multicolumn{1}{c}{ Descrição do material genético } & Fonte do material & Procedência \\
\hline 1 & E. urograndis - clone SVR 3709 & VCP /Fibria & Hulha Negra, RS \\
2 & E. grandis - mudas comerciais (sementes) & Viveiro Tecnoplanta & Barra do Ribeiro, RS \\
3 & E. dunnii - cultivar BRS 9402 (sementes) & Embrapa Florestas & Ponta Grossa, PR \\
4 & E. benthamii - cultivar BRS 8801(sementes) & Embrapa Florestas & Colombo, PR \\
5 & E. badjensis - sementes de talhão experimental manejado & Embrapa Florestas & Ponta Grossa, PR \\
\hline
\end{tabular}

As mudas de cada uma das cinco espécies foram plantadas em setembro de 2005 em uma área de pastagem nativa, após o combate de formigas cortadeiras, utilizando adubação por cova de $100 \mathrm{~g}$ de $\mathrm{P}_{2} \mathrm{O}_{5}$. Dois meses após o plantio foi feita uma adubação de cobertura com $50 \mathrm{~g}$ de $\mathrm{N}$ e $20 \mathrm{~g}$ de $\mathrm{K}_{2} \mathrm{O}$.

No ano seguinte, foi feita a semeadura mecanizada (15 kg ha-1) de braquiária (Urochloa brizanta cv. Marandu), respeitando uma distância mínima de um metro das linhas de árvores. Nesse sistema de integração floresta-pecuária (sistema silvipastoril) foram utilizadas linhas de plantio triplas, distanciadas entre si em $30 \mathrm{~m}$, formando corredores destinados às pastagens e criação de bovinos ou ovelhas. A distância entre as linhas triplas de plantio foi de 3,0 $\mathrm{m}$ e o espaçamento entre plantas nas linhas foi de $2 \mathrm{~m}$, resultando numa densidade inicial de 417 árvores ha ${ }^{-1}$. Esse delineamento correspondeu a $22,2 \%$ de área ocupada pelas faixas dos renques das árvores, sendo o restante destinado à atividade pecuária $(77,8 \%)$. A área total do experimento ocupou em torno de 7 ha (aproximadamente 1,4 ha por espécie). Foi realizada uma desrama no componente florestal (poda dos ramos laterais das árvores) até uma altura de $3 \mathrm{~m}$, aos dois anos de idade, visando agregar valor à madeira e diversificar o uso da madeira também para serraria.

Para se determinar as variáveis de crescimento, foram instaladas seis parcelas retangulares ( $9 \mathrm{~m} \mathrm{x} 14 \mathrm{~m}$ ) com 21 plantas cada, abrangendo as três fileiras de árvores, distribuídas de forma aleatória ao longo dos renques, totalizando 126 árvores por espécie. As mensurações 
foram feitas anualmente, a partir da implantação até os sete anos de idade, onde foram medidos todos os diâmetros a 1,30 m do solo (DAP - cm), com fita diamétrica, e todas as alturas das árvores (m), com hipsômetro Vertex. O volume de madeira produzida $\left(\mathrm{m}^{3} \mathrm{ha}^{-1}\right.$, com casca) foi calculado segundo Oliveira et al. (2011), pela equação 1 .

$$
\mathrm{V}=0,7854 \mathrm{fDAP}^{2} \mathrm{H}
$$

Em que: $\mathrm{V}=$ volume de madeira, com casca, $\mathrm{f}=$ fator de forma $(0,45), \mathrm{DAP}=$ diâmetro a $1,30 \mathrm{~m}$ do solo e $\mathrm{H}=$ altura da árvore.

Em virtude da distribuição espacial das espécies de eucalipto em renques triplos em campo, o delineamento experimental utilizado foi inteiramente casualizado, com seis repetições por tratamento. Para realizar os cálculos das médias dos dados dendrométricos, estimar os volumes totais de madeira produzida $\left(\mathrm{m}^{3} \mathrm{ha}^{-1}\right)$ por espécie, desvio padrão, análises de variância (ANOVA) e comparação de médias pelo teste de Tukey $(\mathrm{p}<0,05)$, foi utilizado o software Assistat (Silva \& Azevedo, 2009, 2016).

\section{Resultados}

É possível verificar pela estatística descritiva para o diâmetro a 1,30 m do solo (DAP), aos sete anos de idade (Tabela 2), que a maior amplitude de diâmetros máximos $(31,2 \mathrm{~cm})$ e mínimos $(6,2 \mathrm{~cm})$ foi obtida para Eucalyptus grandis. As menores médias diamétricas foram observadas em E. badjensis (13,0 $\mathrm{cm} \pm 2,5)$. Observa-se em relação ao desvio-padrão que $E$. urograndis e E. badjensis apresentaram os menores resultados dentre as cinco espécies testadas, com 2,6 e $2,5 \mathrm{~cm}$, respectivamente, sendo o maior obtido para $E$. grandis $(5,9 \mathrm{~m})$.

Pode-se observar que as máximas alturas (Tabela 3 ) foram obtidas para $E$. grandis $(25,8 \mathrm{~m})$, seguida do híbrido $E$. urograndis $(24,7 \mathrm{~m})$. Entretanto, com relação às médias em altura, as posições se invertem entre as duas espécies, com o híbrido apresentando a maior altura média $(21,8 \mathrm{~m})$. E. badjensis foi a espécie que apresentou a menor altura máxima $(15,2 \mathrm{~m})$ e também a menor altura mínima (5,2 m). Com relação ao desvio-padrão, observase que $E$. urograndis e E. badjensis apresentaram as menores variações dentre as cinco espécies testadas, com $2,1 \mathrm{~cm}$ e $2,4 \mathrm{~cm}$, respectivamente, sendo o maior desvio-padrão observado para E. grandis (4,3 m).
Tabela 2. Estatísticas descritivas para diâmetro a 1,30 m acima do nível do solo (DAP) e seus respectivos desvios-padrão (DSVPAD), para as cinco espécies de Eucalyptus, mensuradas aos sete anos de idade, no município de Alegrete, RS.

Table 2. Descriptive statistics for diameter at $1.30 \mathrm{~m}$ above soil level (DAP) and their respective standard deviations (DSVPAD), for the five Eucalyptus species, measured at seven years of age, in Alegrete, Rio Grande do Sul State.

\begin{tabular}{ccccc}
\hline \multirow{2}{*}{ Espécies } & \multicolumn{4}{c}{ DAP $(\mathbf{c m})$} \\
\cline { 2 - 5 } & Máximo & Mínimo & Média & DSVPAD \\
\hline E. urograndis & 27,1 & 10,2 & 18,5 & 2,6 \\
E. grandis & 31,2 & 6,2 & 19,7 & 5,9 \\
E. dunni & 28,5 & 7,3 & 18,4 & 4,9 \\
E. benthamii & 29,4 & 8,1 & 17,2 & 5,3 \\
E. badjensis & 17,8 & 7,3 & 13,0 & 2,5 \\
\hline
\end{tabular}

Tabela 3. Estatísticas descritivas para altura total e seus respectivos desvios-padrão (DSVPAD), para as cinco espécies de Eucalyptus, mensuradas aos sete anos de idade, no município de Alegrete, RS.

Table 3. Descriptive statistics for total height and their respective standard deviations (DSVPAD), for the five Eucalyptus species, measured at seven years of age, in Alegrete, Rio Grande do Sul State.

\begin{tabular}{ccccc}
\hline \multirow{2}{*}{ Espécies } & \multicolumn{4}{c}{ Altura total (m) } \\
\cline { 2 - 5 } & Máxima & Mínima & Média & DSVPAD \\
\hline E. urograndis & 24,7 & 9,6 & 21,8 & 2,1 \\
E. grandis & 25,8 & 7,9 & 20,0 & 4,3 \\
E. dunni & 21,9 & 7,8 & 17,8 & 3,2 \\
E. benthamii & 21,8 & 5,8 & 15,3 & 3,7 \\
E. badjensis & 15,2 & 5,2 & 11,3 & 2,4 \\
\hline
\end{tabular}

$\mathrm{Na}$ Tabela 4 são apresentados os resultados das médias das avaliações dendrométricas e os respectivos percentuais de sobrevivência para as cinco espécies de eucalipto. Os maiores percentuais de sobrevivência foram obtidos para $E$. urorandis e $E$. grandis, com $95 \%$ e $84 \%$, respectivamente. O pior desempenho foi registrado para $E$. badjensis, sendo registrados apenas $29 \%$ de sobrevivência.

Com relação ao desenvolvimento em altura (Tabela 4), o melhor resultado foi observado para o híbrido $E$. urograndis, sendo que no outro extremo, com o pior crescimento, ficou E. badjensis. As demais espécies tiveram desenvolvimento em altura intermediário, na seguinte ordem decrescente: E. grandis, E. dunnii e E. benthamii.

Para o crescimento em DAP, não se observou diferenças significativas entre $E$. urograndis, E. grandis 
e E. dunnii, que apresentaram os melhores resultados. Também é possível observar (Tabela 4), que a média em diâmetro de E. grandis diferiu significativamente das médias de E. benthamii e E. badjensis.

As maiores médias de crescimento em volume (Tabela 4) foram obtidas para E. urograndis e E. grandis, e diferiram estatisticamente de E. dunnii e E. benthamii, que apresentaram volumes intermediários $\left(72,46 \mathrm{~m}^{3} \mathrm{ha}^{-1}\right.$ e $59,57 \mathrm{~m}^{3} \mathrm{ha}^{-1}$, respectivamente). Em razão do alto percentual de mortalidade (71\%) e baixos desempenhos em altura e diâmetro, E. badjensis produziu apenas cerca de $10 \%$ do volume das duas melhores espécies $(10,05$ $\left.\mathrm{m}^{3} \mathrm{ha}^{-1}\right)$.

Tabela 4. Médias obtidas para altura, diâmetro a 1,30 m acima do nível do solo (DAP), sobrevivência e volume das cinco espécies de Eucalyptus mensuradas aos sete anos de idade, no município de Alegrete, RS.

Table 4. Mean values obtained for total height and diamenter at $1.30 \mathrm{~m}$ above soil level (DAP), survival and wood volume for the five Eucalyptus species, measured at seven years of age, in Alegrete, Rio Grande do Sul State.

\begin{tabular}{ccccc}
\hline Espécies & $\begin{array}{c}\text { Altura } \\
(\mathbf{m})\end{array}$ & $\begin{array}{c}\text { DAP } \\
\mathbf{( c m )}\end{array}$ & $\begin{array}{c}\text { Sobrevivência } \\
\mathbf{( \% )}\end{array}$ & $\begin{array}{c}\text { Volume } \\
\left(\mathbf{m}^{3}\right)\end{array}$ \\
\hline E. urograndis & $21,8 \mathrm{a}$ & $18,5 \mathrm{ab}$ & $95 \mathrm{a}$ & $111,9 \mathrm{a}$ \\
E. grandis & $20,0 \mathrm{~b}$ & $19,7 \mathrm{a}$ & $84 \mathrm{a}$ & $115,8 \mathrm{a}$ \\
E. dunnii & $17,8 \mathrm{c}$ & $18,4 \mathrm{ab}$ & $71 \mathrm{~b}$ & $72,5 \mathrm{~b}$ \\
E. benthamii & $15,3 \mathrm{~d}$ & $17,2 \mathrm{~b}$ & $72 \mathrm{~b}$ & $59,6 \mathrm{~b}$ \\
E. badjensis & $11,3 \mathrm{e}$ & $13,0 \mathrm{c}$ & $29 \mathrm{c}$ & $10,1 \mathrm{c}$ \\
\hline CV\% & 5,4 & 8,0 & 10,1 & 18,7 \\
\hline
\end{tabular}

Letras iguais, na coluna, não diferem estatisticamente entre si para as médias em altura, DAP, sobrevivência e volume das cinco espécies testadas ao nível de 5\% de significância, pelo teste de Tukey. CV = coeficiente de variação.

\section{Discussão}

Analisando-se os resultados obtidos na estatística descritiva tanto para o DAP (Tabela 2) quanto para a altura total das árvores (Tabela 3), pode-se observar maior homogeneidade no híbrido Eucalyptus urograndis, em relação às outras espécies que foram propagadas por sementes, a exceção de E. badjensis, que também apresentou pequeno desvio-padrão em DAP e altura $(2,48 \mathrm{~cm}$ e $2,42 \mathrm{~m})$. Normalmente, espera-se maior homogeneidade dos resultados de material clonal em relação ao de propagado por sementes. O plantio de mudas produzidas via propagação vegetativa apresenta, normalmente, maior uniformidade quando as condições de solo e clima se apresentam homogêneas e semelhantes às da origem do material genético selecionado (Ferrari et al., 2004).

Os plantios de espécies florestais com mudas provenientes de sementes possuem maior variabilidade genética e, consequentemente, maior variabilidade fenotípica dos indivíduos (Andrade \& Angelo, 2016). $\mathrm{O}$ crescimento das árvores é influenciado diretamente pelos fatores genéticos da espécie, interagindo com o meio ambiente, com fatores climáticos, solo, topografia, competição e eficiência nutricional (Pinto et al., 2011),

Além disso, espera-se desenvolvimento superior em incremento, quando se comparam mudas provenientes de clones, ou seja, material genético melhorado, e mudas provenientes de sementes, com variabilidade genética ampla (Andrade \& Angelo, 2016). No presente estudo essa tendência não foi observada (Tabela 4). $\mathrm{O}$ material clonal (E. urograndis) foi superior somente em altura, quando comparado ao material seminal de E. grandis. Entretanto, esse mesmo comportamento de superioridade não foi observado para os crescimentos em diâmetro e volume, cujas médias não apresentaram diferenças significativas entre si. Vale uma ressalva, no que diz respeito aos dois materiais comparados, pois a constituição genética do híbrido não é a mesma do material seminal, apesar da presença da espécie $E$. grandis nos dois germoplasmas.

Por outro lado, de acordo com Pinto et al. (2011), mudas seminais podem ter maior desenvolvimento quando comparadas com mudas clonais. Isto pode ocorrer pela interação clone $\mathrm{x}$ ambiente, de forma que genótipos superiores podem não apresentar os mesmos resultados positivos em ambientes distintos, principalmente em relação à eficiência nutricional.

$O$ crescimento volumétrico do híbrido $E$. urograndis e de $E$. grandis foi superior ao das demais espécies (Tabela 4). Esse desempenho era esperado, pois E. grandis caracteriza-se por apresentar alta produtividade, quando comparado à outras espécies do gênero (Barreiros et al., 2007; Souza \& Fiorentin, 2013; Ferreira et al., 2017).

Em virtude disso, e da sua versatilidade e qualidade da madeira para uso múltiplo, E. grandis é a espécie com maior área plantada no Brasil, quando também se consideram os híbridos formados com essa espécie. Da mesma forma, devido às suas características de superioridade, essa espécie também está amplamente disseminada em outros países da América, da África e da Ásia (Higa et al., 2009; Souza \& Fiorentin, 2013). 
O híbrido $E$. urograndis é um dos mais utilizados pelas empresas de papel e celulose no País. Uma vez que o cruzamento entre essas duas espécies resultou em árvores com rápido crescimento, característica de $E$. grandis, e aumento da densidade da madeira, rusticidade e tolerância ao estresse hídrico e a geadas, características de E. urophylla (Mori et al., 1988; Moraes et al., 2016). Outras qualidades desse híbrido são: excelente vigor, propriedades tecnológicas da madeira adequadas a múltiplos usos, além de resistência a doenças e facilidade de enraizamento (Paludzyszyn Filho \& Santos, 2011).

De acordo com Ryan et al. (2010) e Schumacher et al. (2011), verifica-se grande dinamismo e variabilidade no comportamento produtivo entre as regiões cultivadas com espécies do gênero Eucalyptus, o que está, normalmente, relacionado ao tipo de clima, à disponibilidade hídrica e fertilidade dos solos, densidade do plantio e idade do povoamento.

O Estado do Rio Grande do Sul apresenta condições edafoclimáticas bastante distintas e, consequentemente, com potencial diferenciado para o desenvolvimento de distintas espécies de Eucalyptus. Na maior parte do Estado, os plantios florestais são realizados principalmente com E. grandis e E. dunnii, este último nas regiões mais frias (Higa et al., 2009).

Dentre as espécies pesquisadas nesse trabalho, $E$. grandis é a que apresenta menor tolerância ao frio. Entretanto, em um trabalho de zoneamento agroclimático do eucalipto para o Estado do Rio Grande do Sul, Wrege et al. (2009) classificaram a região sudoeste do Estado, onde está localizada a área experimental, como sem restrição para o plantio dessa espécie, apesar da possibilidade da existência de estiagens periódicas.

Gonzalez et al. (2011), analisando diversas espécies de eucalipto com tolerância ao frio para uso como bioenergia, identificaram como tendo potencial para crescer no sul dos Estados Unidos, em regiões com clima subtropical, as espécies E. camaldulensis, E. benthamii, E. viminalis, E. macarthurii, E. grandis, E. robusta, E. saligna e o híbrido $E$. urograndis.

Paludzyszyn et al. (2006) ressaltam que E. dunnii apresenta bom comportamento em áreas mais frias e indicam essa espécie para plantio em regiões com temperaturas mínimas absolutas de até $-5{ }^{\circ} \mathrm{C}$, sob condições de aclimatação prévia por gradual redução de temperatura na estação fria, o que permitiria suportar até 22 geadas anuais.
Yu \& Gallagher (2015), analisando o ritmo de crescimento e a tolerância ao frio de um povoamento de $E$. benthamii, com cinco anos de idade no estado do Alabama, EUA, em uma área com clima subtropical úmido, concluíram que a espécie foi considerada tolerante a uma temperatura de $-7,4^{\circ} \mathrm{C}$.

$\mathrm{Na}$ Austrália, em vários testes realizados com diferentes germoplasmas do gênero Eucalyptus, E. dunnii superou espécies tradicionalmente plantadas no País, como E. grandis e E. pilularis, em avaliações entre 15 e 18 anos de idade, tornando-se uma das espécies estratégicas para plantios em New South Wales (Johnson \& Stanton, 1993).

Em regiões do interior da China com ambiente subtropical, caracterizadas por verões quentes e úmidos e geadas frequentes e eventos frios com temperaturas até $-8^{\circ} \mathrm{C}$ ou inferiores, foram testadas diferentes espécies e procedências de eucaliptos para o desenvolvimento de plantações. Dentre as espécies que demonstraram o melhor crescimento e sobrevivência aos 6 anos estão E. benthamii, E. dunnii e E. dorrigoensis (Arnold et al., 2015).

Segundo Paludzyszyn Filho \& Santos (2013), E. benthamii e E. dunnii são as espécies mais indicadas para plantio em regiões de clima frio e sujeitas à geada no Brasil. E. benthamii é considerada mais tolerante a geadas do que $E$. dunnii e apresenta como vantagens a disponibilidade de sementes e de mudas de clones para plantios comerciais.

E. badjensis também é considerado uma alternativa para plantios na região Sul do Brasil, além de E. dunnii e $E$. benthamii, principalmente em função da tolerância a geadas (Paludzyszyn Filho et al., 2006; Santos et al., 2015). Entretanto, essas espécies, nas condições experimentais de campo, não apresentaram bons desempenhos em termos de percentuais de sobrevivência e crescimento. Com significativos percentuais de mortalidade, aos sete anos de idade, E. benthamii (28\%) e E. dunnii (29\%) se destacam negativamente. O pior desempenho foi registrado para a E. badjensis, com apenas $29 \%$ de sobrevivência (Tabela 4 ).

Resultados semelhantes foram obtidos para $E$. badjensis, na província de Entre Rios, na Argentina, onde duas procedências testadas também apresentaram problemas de adaptação, com baixo percentual de sobrevivência variando de 30 a 60 nos primeiros anos (Harrand et al., 2016). Nesse mesmo estudo, onde 
foram testadas diversas espécies alternativas para regiões mais propensas a geadas severas (nas latitudes entre os paralelos $31^{\circ}$ e $33^{\circ} \mathrm{S}$ ), algumas espécies e procedências se destacaram, apresentando bom potencial de crescimento e tolerância ao frio, como $E$. benthamii, E. dunnii e E. deanei, com percentuais de sobrevivência variando de 81 a 98\%, aos 27 meses de idade. Na área experimental não se observou essa mesma tendência de desempenho para E. dunnii e E. benthamii, devido ao alto percentual de mortalidade (aproximadamente de 30\%). Essas duas espécies também não apresentaram diferenças significativas em volume $\left(\mathrm{m}^{3}\right.$ ha-1) e produziram menores volumes de madeira (em torno de $60 \%$ ) em relação a $E$. urograndis e E. grandis (Tabela 4).

De acordo com Paludzyszyn et al. (2006), apesar de $E$. dunnii apresentar tolerância a geadas, o desenvolvimento da espécie em regiões frias, quando comparado com o crescimento em regiões com clima tendendo para tropical, é significativamente inferior. Esse fato, observado pelos autores, pode contribuir para explicar o baixo desempenho em crescimento observado para essa espécie na região de estudo. Os mesmos autores concluíram, a partir de experimento conduzido em Guarapuava, PR e por comparação com outros trabalhos, que $E$. benthamii é mais resistente às geadas e melhor adaptado às condições de clima frio, justificando o maior crescimento. Porém, isso também não foi observado nesse trabalho, uma vez que as duas espécies apresentaram comportamento semelhante em termos de percentuais de sobrevivência e volume de madeira produzido (Tabela 4).

\section{Conclusões}

Em termos de sobrevivência, crescimento e produtividade, Eucalyptus grandis e o híbrido E. urograndis se destacaram para uso em sistemas de integração floresta-pecuária na região de Alegrete, RS.

Em razão de problemas de adaptação, demonstrado pelo alto percentual de mortalidade e pelo inexpressivo volume de madeira produzido, E. badjensis não deve ser recomendado para plantios em condições análogas à que foi desenvolvida a pesquisa.

\section{Agradecimentos}

A fundação Maronna, entidade não governamental de direito privado, criada com a finalidade de prestar apoio técnico-científico à atividade agropecuária. Ao engenheiro Agrônomo Luiz Plastina Gomes, responsável pela implantação e manutenção e condução do experimento na Estância Sá Brito, local onde foi desenvolvido o estudo. Aos parceiros Carlos Alberto Flores, pesquisador da Embrapa Clima Temperado, e Vilmar Luciano Mattei, professor da Universidade Federal de Pelotas. Ao engenheiro Florestal Leandro Bargas, da Empresa Soluções Florestais (SOLUFOR), pela colaboração no tratamento dos dados coletados e na análise estatística.

\section{Referências}

Alvares, C. A. et al. Köppen's climate classification map for Brazil. Meteorologische Zeitschrift, v. 22, n. 6, p. 711-728, 2013. DOI:10.1127/0941-2948/2013/0507.

Associação Gaúcha de Empresas Florestais. Anuário AGEFLOR 2015. Disponível em: <http://www.ageflor.com.br/noticias/ biblioteca/anuario-ageflor-2015-ano-base-2014.pdf>. Acesso em: 16 jun. 2017

Associação Gaúcha de Empresas Florestais. Anuário AGEFLOR 2016: ano base 2015. Disponível em: $<$ http://www.ageflor.com. br/noticias/wp-content/uploads/2016/09/AGEFLOR-DADOS-EFATOS-2016.pdf>. Acesso em: 16 jun. 2017.

Andrade, R. N. de \& Angelo, A. C. Crescimento inicial de Eucalyptus benthamii Maiden et Cambage Eucalyptus dunnii Maiden., em General Carneiro, PR. 2016. Monografia (Graduação) - Universidade Federal do Paraná. Disponível em: <http://hdl.handle. net/1884/45502>. Acesso em: 16 jun. 2017.

Arnold, R. et al. Selection of cold-tolerant Eucalyptus species and provenances for inland frost-susceptible, humid subtropical regions of southern China. Australian Forestry, v. 78, 2015. DOI: 10.1080/00049158.2015.1063471.

Barreiros, R. M. et al. Modificações na produtividade e nas características físicas e químicas da madeira de Eucalyptus grandis causadas pela adubação com lodo de esgoto tratado. Revista Árvore, v. 31, n. 1, p. 103-111, 2007. DOI: 10.1590/S010067622007000100012 .

Ben, L. H. B. et al. Influence of irrigation levels and plant density on "second-season" maize. Revista Caatinga, v. 29, n. 3, p. 665-676, 2016. DOI: 10.1590/1983-21252016v29n317rc.

Brixner, G. F. et al. Risco de geada e duração dos subperíodos fenológicos da 'Cabernet Sauvignon' na região da Campanha. Revista Brasileira de Engenharia Agrícola e Ambiental, v. 18, n. 2, p. 217-224, 2014.

Caron, B. O. et al. Resistência inicial de quatro espécies arbóreas em diferentes espaçamentos após ocorrência de geada. Ciência Rural, v. 41, n. 5, p. 817-822, 2011. DOI: 10.1590/S010384782011000500013.

Carvalho, P. C. F. et al. Produção animal no bioma campos sulinos. Brazilian Journal of Animal Science, v. 35, n. supl. esp., p. 156202, 2006. 
Costa, L. B. et al. Viabilidade econômica: análise da bovinocultura de corte. Informações Econômicas, v. 36, n. 8, 2006.

Ferrari, M. P. et al. Propagação vegetativa de espécies florestais. Colombo: Embrapa Florestas, 2004. 22 p. (Embrapa Florestas. Documentos, 94).

Ferreira, D. H. A. A. et al. Crescimento e produção de eucalipto na região do médio Paraíba do Sul, RJ. Floresta e Ambiente, v. 24, e00131315, 2017. DOI: 10.1590/2179-8087.131315.

Flores, C. A. et al. Sistema agrossilvipastoril na região sudoeste do estado do Rio Grande do Sul. 2010. Disponível em: <www. infobibos.com/Artigos/2010 4/SistemaAgroSilvoPastoril/index. $\mathrm{htm}>$. Acesso em: 20 maio 2016.

Gonzalez, R. et al. Exploring the potential of Eucalyptus for energy production in the Southern United States: Financial analysis of delivered biomass. Part I. Biomass and Bioenergy, v. 35, p. 755766, 2011. DOI: 10.1016/j.biombioe.2010.10.011.

Harrand, L. et al. Evaluación de comportamiento de especies de eucaliptos en ambientes de Entre Ríos. In: REUNIÓN GEMFO, 7., 2016, San Miguel de Tucumán, Tucumán. [Actas...]. San Miguel de Tucumán, 2016. <https://www.researchgate.net/ publication/307572066_Performance_of_eucalypts_species_in_ environments_of_Entre_Rios>. Acesso em: 20 maio 2016.

Higa, R. C. V. et al. Características de algumas espécies de eucaliptos. In: Flores, C. A. et al. (Org.). Zoneamento agroclimático do eucalipto para o estado do Rio Grande do Sul e edafoclimático na região do Corede Sul - RS. Pelotas: Embrapa Clima Temperado, 2009. v. 1. p. 41-44.

Ilha, A. S. et al. Desigualdades regionais no Rio Grande do Sul: o caso da metade sul. In: PRIMEIRO ENCONTRO DE ECONOMIA GAÚCHA, 1., 2006, Porto Alegre. Anais... Porto Alegre: PUCRS/ FEE, 2006. 21 p.

Inácio, R. P. \& Senna, A. J. T. Caracterização da cadeia produtiva da madeira no município de Rosário do Sul-RS. Organizações Rurais \& Agroindustriais, v. 16, n. 3, p. 291-305, 2014.

Johnson, I. G. \& Stanton, R. R. Thirty years of eucalypt species and provenance trials in New South Wales: survival and growth in trials established from 1961 to 1990. Sydney: Forestry Commission of New South Wales, 1993. (Research paper, 20).

Köppen, W. Das geographische system der klimate. In: Köppen, W.; Geiger, R. (Ed.). Handbuch der klimatologie. Berlin: Gebrüder Bornträger, 1936. p. 1-44.

Maluf, J. R. T. Nova classificação climática do Estado do Rio Grande do Sul. Revista Brasileira de Agrometeorologia, v. 8, n. 1, p. 141-150, 2000.

Matzenauer, R. et al. (Ed.). Atlas climático: Porto Alegre: FEPAGRO, 2011.

Moraes, C. B. et al. Variabilidade genética em progênies de meiosirmãos de eucaliptos para tolerância ao frio. Revista Árvore, v. 39, p. 1047-1054, 2015. DOI:10.1590/0100-67622015000600007.

Moraes, C. B. et al. Controle genético para a tolerância a geada em progênies de Eucalyptus urophylla. Scientia Forestalis, v. 44, p. 373-381, 2016. DOI: 10.18671/scifor.v44.n110.10.
Mori, E. S. et al. Variação genética e interações progênies x locais em Eucalyptus urophylla. IPEF, v. 39, p. 53-63, 1988.

Nabinger, C. et al. Produção animal em campo nativo: aplicações de resultados de pesquisa. In: Pillar, V. P. et al (Ed.). Campos sulinos: conservação e uso sustentável da biodiversidade. Brasília, DF, 2009. p. 175-198.

Oliveira, E. B. et al. Determinação da quantidade de madeira, carbono e renda da plantação florestal. Colombo: Embrapa Florestas, 2011. 37 p. (Embrapa Florestas. Documentos, 220).

Paludzyszyn Filho, E. et al. Eucaliptos indicados para plantio no Estado do Paraná. Colombo: Embrapa Florestas, 2006 (Embrapa Florestas. Documentos, 129).

Paludzyszyn Filho, E. \& Santos, P. E. T. dos. Programa de melhoramento genético de eucalipto da Embrapa Florestas: resultados e perspectivas. Colombo: Embrapa Florestas, 2011. 64 p. (Embrapa Florestas. Documentos, 214).

Paludzyszyn Filho, E. \& Santos, P. E. T. dos. Escolha de cultivares de eucaliptos em função do ambiente e do uso. Colombo: Embrapa Florestas, 2013. 11 p. (Embrapa Florestas. Comunicado técnico, 316).

Peel, M. C. et al. Updated world map of the Köppen-Geiger climate classification. Hydrology and Earth System Sciences Discussions, v. 11, n. 5, p. 1633-1644, 2007.

Pinto, S. I. C. et al. Eficiência nutricional de clones de eucalipto na fase de mudas cultivados em solução nutritiva. Revista Brasileira de Ciência do Solo, v. 35, p. 523-533, 2011. DOI: 10.1590/S010006832011000200021.

Ribaski, S.A.G. et al. Sistemas silvipastoris com apoio ao desenvolvimento rural para a Região Sudoeste do Rio Grande do Sul. Pesquisa Florestal Brasileira, v. 60, p. 27-37, 2009. DOI: 10.4336/2009.pfb.69.27.

Ryan, M. G. et al. Factors controlling Eucalyptus productivity: how water availability and stand structure alter production and carbon allocation. Forest Ecology and Management, v. 259, n. 9, p. 16951703, 2010. DOI: 10.1016/j.foreco.2009.01.013.

Ruviaro, C. F. et al. Economic and environmental feasibility of beef production in different feed management systems in the Pampa biome, southern Brazil. Ecological Indicators, v. 60, p. 930-939, 2016. DOI: 10.1016/j.ecolind.2015.08.042.

Santos, H. G. dos et al. Sistema brasileiro de classificação de solos. 3. ed. Brasília, DF: Embrapa, 2013. 353 p.

Santos, P. E. T. et al. Genetic variation for growth and selection in adult plants of Eucalyptus badjensis. Genetics and Molecular Biology, v. 38, p. 457-464, 2015. DOI: 10.1590/S1415-475738420150041.

Schumacher, M. V. et al. Biomassa em povoamentos de Eucalyptus spp. de pequenas propriedades rurais em Vera Cruz - RS. Ciência Florestal, v. 21, n. 1, p. 17-22, 2011. DOI: 10.5902/198050982743.

Silva, A. L. L. et al. Tolerância ao resfriamento e congelamento de folhas de eucalipto. Biociências, v. 17, n. 1, p. 86-90, 2009.

Silva, F. de A. S. \& Azevedo, C. A. V. de. Principal components analysis in the Software Assistat-Statistical Attendance. In: WORLD CONGRESS ON COMPUTERS IN AGRICULTURE, 7, Reno. Proceedings... Reno: American Society of Agricultural and Biological Engineers, 2009. 
Silva F. de A. S. \& Azevedo, C. A. V. The Assistat Software Version 7.7 and its use in the analysis of experimental data. African Journal of Agricultural Research, v. 11, n. 39, p. 3733-3740, 2016. DOI: 10.5897/AJAR2016.11522.

Soares, F. C. et al. Irrigação suplementar na produção de grãos e na eficiência de uso da água do feijoeiro. Revista Agrarian, v. 9, n. 34, p. 374-382, 2016.

Souza, J. T. de. \& Fiorentin, L. D. Quantificação da biomassa e do carbono em povoamento de Eucalyptus grandis W. Hill ex Maiden, em Santa Maria, RS. Unoesc \& Ciência, v. 4, n. 2, p. 253-262, 2013.

Varella, A. C. et al. Estabelecimento de plantas forrageiras em sistemas de integração floresta-pecuária no Sul do Brasil. In. Fontaneli, R. S. et al. (Ed.). Forrageiras para integração lavourapecuária-floresta na região sul-brasileira. 2. ed. Brasília, DF: Embrapa, 2012. p. 435-460.
Varella, A. C. et al. Silvopastoral systems in the Cold Zone of Brazil. In: Peri, P. L. et al. (Org.). Advances in agroforestry: silvopastoral systems in Southern South America. [Cham]: Springer International Publishin, 2016. v. 1. p. 231-255.

Wrege, M. S. et al. Zoneamento Agroclimático para o eucalipto no Estado do Rio Grande do Sul. In: Flores, C. A. et al. (Org.). Zoneamento agroclimático do eucalipto para o estado do Rio Grande do Sul e edafoclimático na região do Corede Sul - RS. Pelotas: Embrapa Clima Temperado, 2009. v. 1. p. 51-56.

Yu, A. \& Gallagher, T. Analysis on the growth rhythm and cold tolerance of five-year old Eucalyptus benthamii plantation for bioenergy.. Open Journal of Forestry, v. 5, n. 6. p. 585-592, 2015. DOI: $10.4236 /$ ojf.2015.56052. 